\title{
3D PHYSICAL MODELING OF TSUNAMIS GENERATED BY SUBMERGED LANDSLIDES AT A CONICAL ISLAND: THE ROLE OF INITIAL ACCELERATION
}

\author{
Romano $\mathrm{A}^{1}$, Di Risio $\mathrm{M}^{2}$, Molfetta $\mathrm{MG}^{3}$, Bellotti $\mathrm{G}^{4}$, Pasquali $\mathrm{D}^{5}$, Sammarco $\mathrm{P}^{6}$, Damiani $\mathrm{L}^{7}$, De Girolamo $\mathrm{P}^{8}$
}

This paper presents a new set of 3D experiments aimed to gain insight on the role of the initial acceleration upon the generation process of tsunamis by submerged landslides that may occur at the flanks of conical islands. The experiments have been carried out in a large wave tank by varying the initial acceleration of the landslide model. A novel system, relying on the use of a computer controlled stepped motor, has been employed to control the motion of the landslide model. The experiments have been carried out in a parametric way by changing the initial acceleration of the landslide, aiming to reproduce different triggering mechanisms. Preliminary experimental findings confirmed the crucial role of the initial acceleration of the submerged landslide in generating tsunamis.

Keywords: tsunamis; submerged landslisdes; conical island;

\section{INTRODUCTION}

Landslide-generated tsunamis tend to be local, although extreme, phenomena. Several catastrophic events have been occurred in the past. The events occurred at Lituya Bay (Alaska, July 9, 1958; e.g. Fritz et al., 2009), at Vajont Valley (Italy, October 9, 1963; e.g. Panizzo et al., 2005), in Papua New Guinea in 1998 (e.g. Synolakis et al., 2002), and in Haiti in 2010 (e.g. Fritz et al., 2012) are meaningful examples of such a phenomenon. The triggering mechanism, i.e. the landslide, can be classified as subaerial, partially submerged or completely submerged, depending on the initial landslide position (Di Risio et al., 2011; McFall and Fritz, 2016). Generally, landslide-generated tsunamis takes place on both larger temporal- and smaller spatial-scale if compared with those generated by earthquakes (Di Risio and Sammarco, 2008). These features suggest that tsunamis generated by landslides, both subaerial and submerged, can cause dangerous effects especially when the tsunamigenic events occur in confined areas (e.g. lakes, bays, gulfs, etc.).

This paper focuses on the impulsive waves generation due to submerged landslides that occur at conical islands. Indeed, it can be assumed that this idealized geometry may qualitatively represent small volcanic islands (e.g. Stromboli Island, South Thyrrenian Sea, Italy, Tinti et al., 2005, 2006; Bellotti et al., 2009; De Girolamo et al., 2014). Originally, the study of tsunamis that take place on such a geometry were motivated by the extreme inundation observed in the rear side of Babi Island (Indonesia) during an earthquake induced tsunami attack (December 12, 1992). A series of experiments was performed (e.g. Yeh et al., 1994; Briggs et al., 1995a,b; Liu et al., 1995; Cho and Liu, 1999; Cho et al., 2004) aimed to define inundation maps around a circular island due to the attack of a solitary wave propagating from offshore. When landslides occur directly on the shore, it can be also noticed that the generated transient waves may be trapped close to the coast as edge waves packets (Ursell, 1952; Lynett and Liu, 2005; Johnson, 2007; Romano et al., 2013; Romano, 2014). Then, more recently, the problem of wave generation due to coastal tsunamigenic sources, i.e. coastal landslides, has been tackled by means of theoretical (Sammarco and Renzi, 2008; Renzi and Sammarco, 2010), experimental (e.g. Di Risio et al., 2009a,b; Mohammed and Fritz, 2012; Heller and Spinneken, 2015; Heller et al., 2016; McFall and Fritz, 2016; Zitti et al., 2016) and numerical modeling (e.g. Cecioni and Bellotti, 2010; Cecioni et al., 2011; Montagna et al., 2011) in the case of both straight coast and circular island.

Nevertheless, most of the researches cited so far dealt with subaerial gravity driven landslide. It is worth noticing that the features of the impulsive waves generated by underwater landslides are significantly different, especially in the near-field, from that induced by subaerial ones. As experimentally observed by Enet and Grilli (2007), if a submerged landslide occurs, a wave trough takes place above the initial position of the slide itself. The rebound of such a depression causes perturbations that both radiate offshore and propagate shoreward. Several works have addressed the study of impulsive waves generated by submerged

\footnotetext{
1“La Sapienza" University of Rome, Italy, email: alessandro.romano@uniroma1.it

${ }^{2}$ University of L'Aquila, Italy

${ }^{3}$ Polytechnic of Bari, Italy

${ }^{4}$ Roma Tre University, Italy

${ }^{5}$ University of L'Aquila, Italy

'University of Rome "Tor Vergata", Italy

${ }^{7}$ Polytechnic of Bari, Italy

8"La Sapienza" University of Rome, Italy
} 


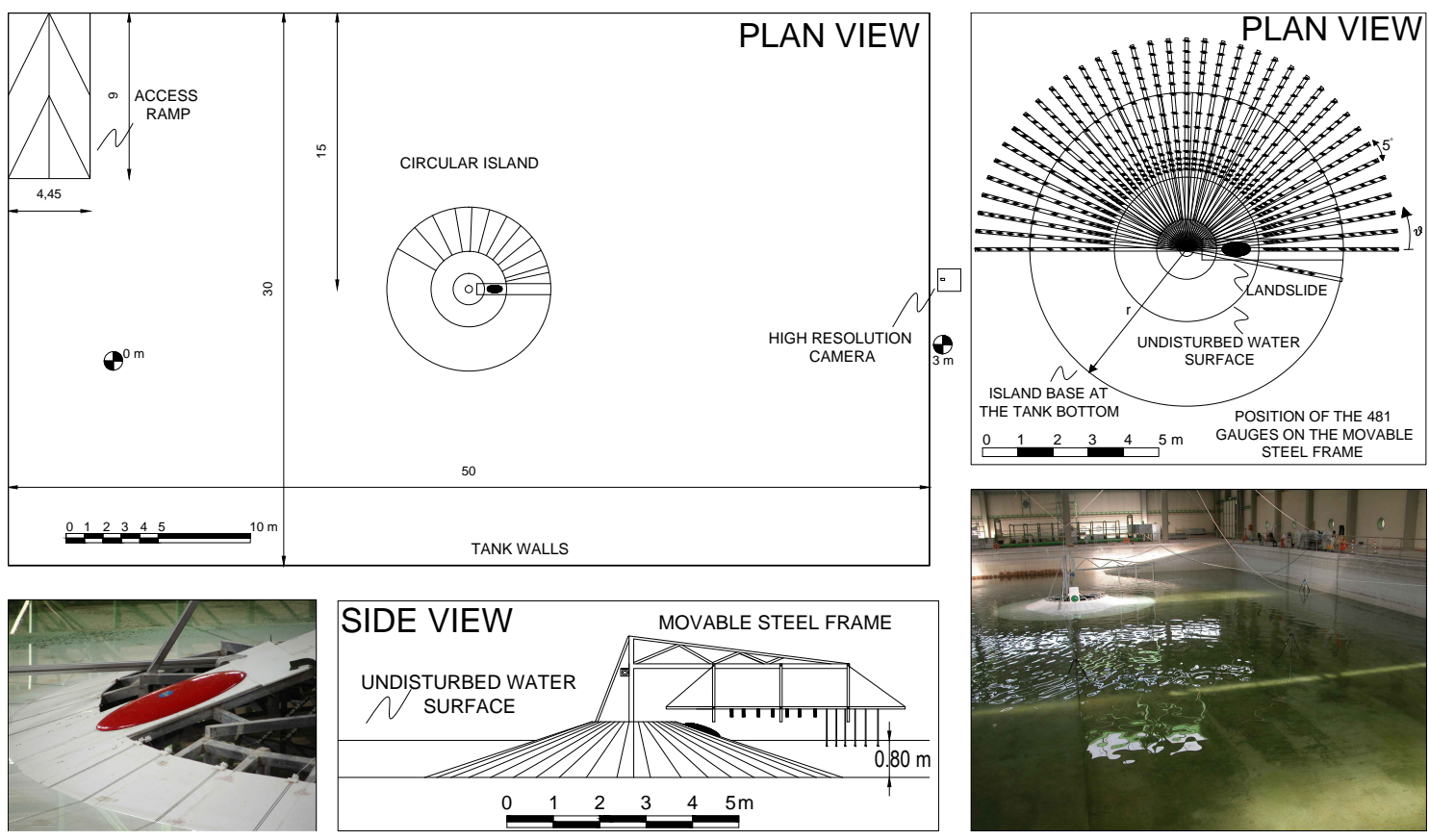

Figure 1: Sketch and pictures of the experimental set-up (adapted from Romano et al., 2016).

landslides (e.g. Watts, 1998; Grilli and Watts, 2003; Grilli and Watts, 2005; Enet et al., 2003; Liu et al., 2005; Lynett and Liu, 2005; Enet and Grilli, 2007). It is worth noticing the work of Watts (1998) that, based also on the theoretical analysis of solid block motion proposed by Pelinovsky and Poplavsky (1996) and by means of dimensional analysis and 2D physical experiments, provided both the analytical solution of the underwater motion of a solid block and a nondimensional wavemaker curve of tsunamis generated by submarine landslide as a function of the initial submergence, of the terminal velocity $u_{t}$ and of the initial acceleration $a_{0}$ of the landslide. Hence, the key result of Watts (1998) consists in the formal coupling of the landslide motion to the generated waves (dimensionless wavemaker curve). Indeed, it is commonly accepted that the initial acceleration $a_{0}$ is the "most important factor controlling tsunami generation by rigid underwater slides" (Grilli and Watts, 2005; Enet and Grilli, 2007), as further concluded by Løvholt et al. (2015). From a physical point of view, the initial acceleration is related to the landslide triggering mechanisms (e.g. related to the action of gravity, earthquakes, soil liquefaction, etc.), and then to the generated tsunami features.

This paper describes a new set of 3D experiments aimed to gain insight on the role of the initial acceleration $a_{0}$ in the generation process of tsunamis generated by submerged landslides that occur at the flanks of conical islands. The experiments have been carried out in a large wave tank by using the same physical model described by Di Risio et al. (2009b) and Romano et al. (2016). It is worth noticing that within the previous experimental campaigns only subaerial landslides have been studied. Herein, in order to generate the impulsive waves with varying initial acceleration, a novel system has been conceived. An electric motor has been employed for controlling the motion of the landslide model. The experiments have been carried out in a parametric way by changing the initial acceleration $a_{0}$ of the landslide, aiming to simulate different triggering mechanisms other than the gravity. The laws of motion of the landslide model used during the experiments have been defined on the basis of the theoretical works of Pelinovsky and Poplavsky (1996) and Watts (1998). The main purpose of the experiments consists in studying in details the wave features in the near-field, therefore the high-spatial resolution measurement system described in Romano et al. (2016) has been used.

The paper is structured as follows. The description of the experimental set-up and of the landslides' laws of motion are given in the next sections. Then an overview of the preliminary results follows. Finally, concluding remarks and ongoing research close the paper. 

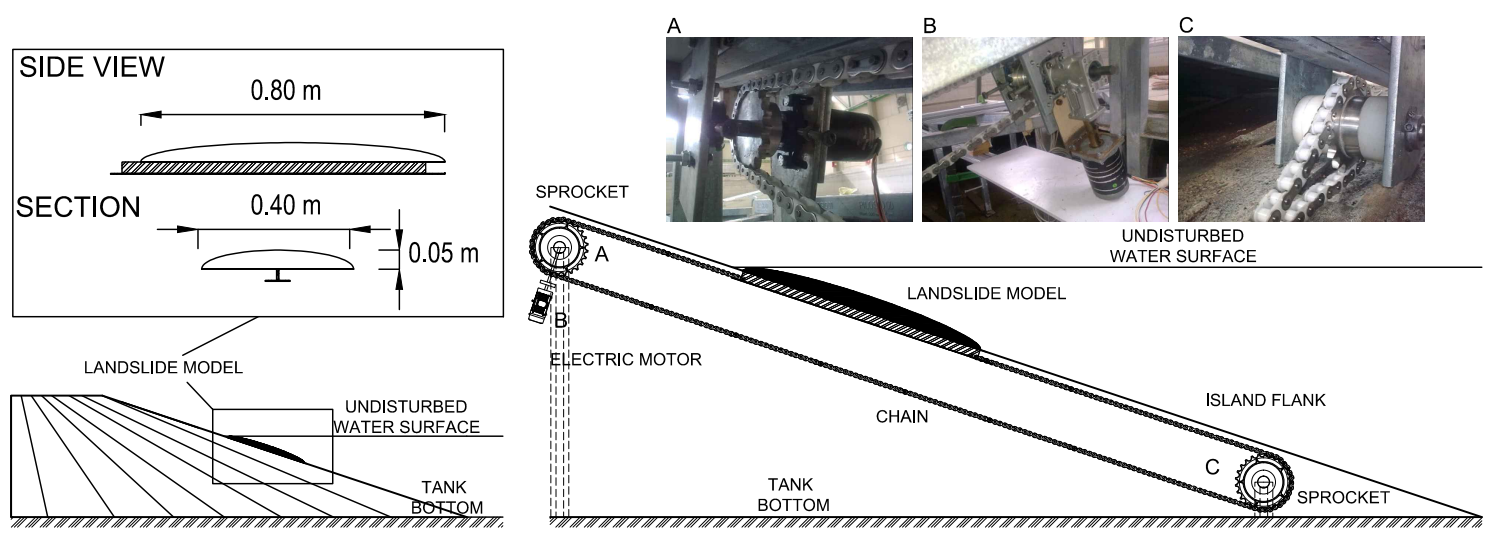

Figure 2: Sketch and pictures of both the landslide model and the electric system (motor, chain and sprockets) used for moving the submerged landslide model.

\section{EXPERIMENTAL SET-UP}

The experiments have been carried out in a large wave tank ( $30.0 \mathrm{~m}$ long, $50.0 \mathrm{~m}$ wide and $3.0 \mathrm{~m}$ deep). The physical model consisted of a truncated conical island (base radius equal to $4.50 \mathrm{~m}$, maximum height equal to $1.20 \mathrm{~m}$, see Figure 1) placed at the center of the tank. The water depth has been kept constant to $0.80 \mathrm{~m}$. The slope of the flanks of the island is $1 / 3$ ( 1 vertical, 3 horizontal). The landslide model (Figure 2) has a regular shape that reproduces a half of an ellipsoid (total mass equal to $15.40 \mathrm{~kg}$ ). As outlined, the experiments aimed to measure the waves generated by the submerged landslide model if the initial acceleration $a_{0}$ is varied. Hence, a novel system for controlling the landslide motion has been conceived. The displacement of the landslide was controlled by an electric motor that drives a system, placed in the inner part of the physical model of the conical island, that consists in a chain and two sprockets (Figure 2). The lower part of the landslide model is welded to the chain and thus the model is constrained to move on rails placed parallel along the slope. The electric motor is controlled by a PC. The motion of the landslide, that has been defined during the experiments, are described in the next section.

To measure the water level around the island, the high spatial resolution measurement system described by Romano et al. (2016) has been used. For the sake of clarity we briefly provide a description of the movable measurement system. Indeed, the measurement system (see Figure 1) allowed to collect the free surface time series along cross-shore sections, starting from the axis along which the landslide moves $(\theta=$ $\left.0^{\circ}\right)$ up to the rear side of the island $\left(\theta=180^{\circ}\right)$. For each test, the landslide was placed at its starting position and the movable steel frame moved to the correct angular position, then the acquisition process began, the landslide model slid down the slope and the tsunami was generated. The procedure was repeated for each position of the movable frame. As the research presented herein is devoted to the analysis of the wave features in the near-field, the configuration of the movable frame ranged from $\theta=0^{\circ}$ up to $\theta=15^{\circ}$ (with an angolar resolution equal to $5^{\circ}$ ). Furthermore, fixed sensors have been used to check the repeatability of the tests. In particular: (a) 12 run-up gauges were embedded directly into the PVC of the island flanks in order to measure the shoreline displacements time series; (b) 9 wave gauges were placed in fixed position near the generation area and in the far field; (c) 7 ultrasound sensors and 6 wave gauges were placed on the movable frame.

\section{MOTION OF THE LANDSLIDE}

As previously highlighted, the scientific literature commonly recognizes that the initial acceleration $a_{0}$ is one of the most important factor controlling tsunami generation by rigid underwater slides (Grilli and Watts, 2005; Enet and Grilli, 2007; Løvholt et al., 2015). As far as gravity-driven landslides are considered, then $a_{0}$ can be inferred as follows (e.g. Pelinovsky and Poplavsky, 1996):

$$
a_{0}=\frac{\left(m-m_{s 0}\right) g\left(\sin \theta-C_{n} \cos \theta\right)}{m+C_{m} m_{s 0}},
$$

where $g$ is the gravity acceleration, $m$ and $m_{s 0}$ are the mass of the body and the mass of the water displaced respectively, $\theta$ is the angle of the incline, $C_{n}$ is the Coulombic friction coefficient and $C_{m}$ is the added mass 

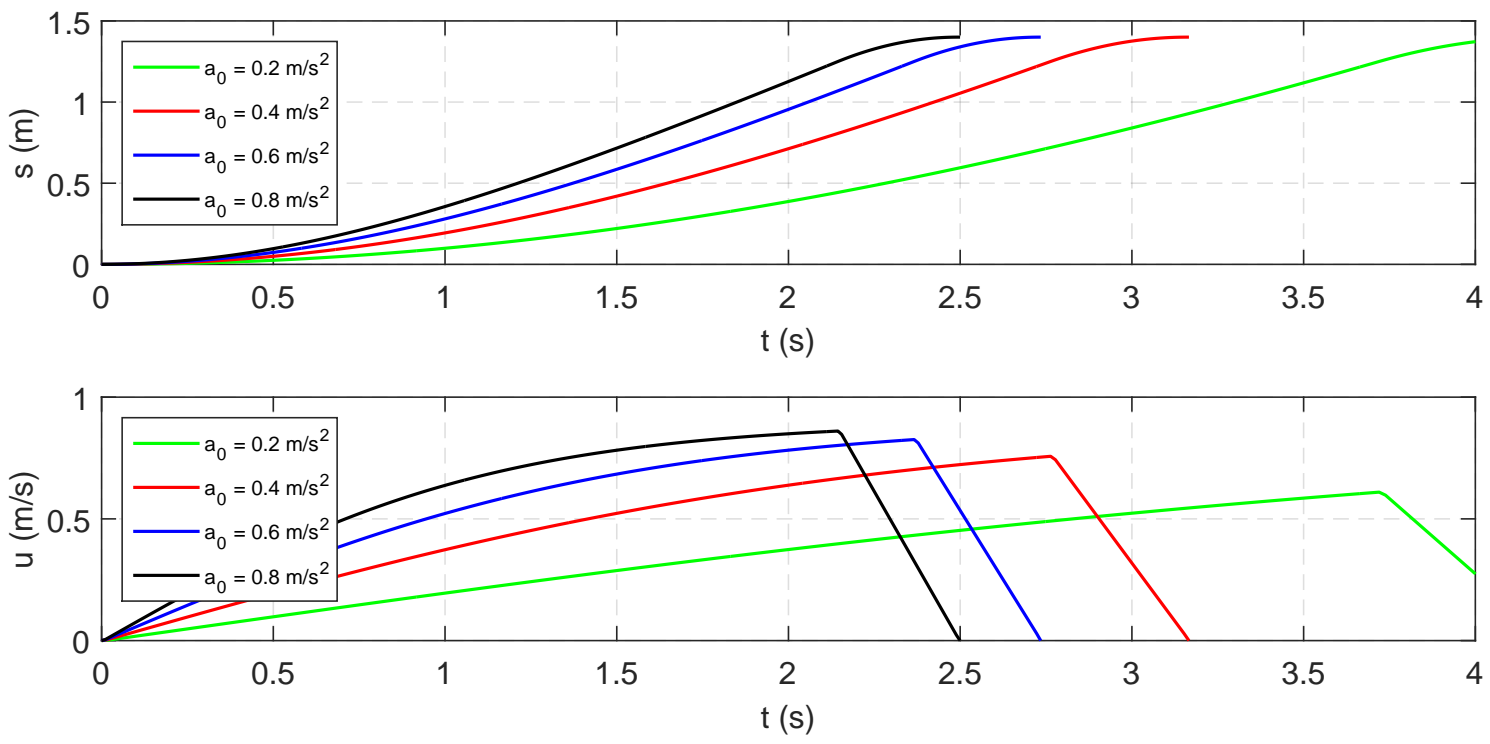

Figure 3: Experimental laws of motion of the landslide as a function of the initial acceleration $a_{0}$.

coefficient. By following (1), Watts (1998) performed a set of 2D experiments by changing the mass of the slide (by keeping constant the volume) in order to vary the initial acceleration.

It is almost clear that initial acceleration given by (1) is able to describe only the instability processes that may trigger landslides due to the action of the gravity. Indeed, $a_{0}$ is greater than zero (i.e. the landslides is triggered) only if the slope of the incline is large enough in such a way the gravity action is stronger than the shear strength along the sliding surface (related to the Coulombic friction coefficient).

In the experiments described herein a different approach was employed. A parametric set of experiments was performed by varying the initial acceleration $a_{0}$ of the landslide model (by keeping constant both the mass and the volume) to explore the effects of triggering mechanisms other than the gravity action (e.g. earthquakes, soil liquefaction, ecc.) on the tsunamis features. Four different values of the initial acceleration $a_{0}$ have been used, namely $a_{0}=[0.2,0.4,0.6,0.8] \mathrm{m} / \mathrm{s}^{2}$. It has to be stressed that the initial acceleration related to the gravity action for the used landslide model (see Romano et al., 2016) is equal to about 0.47 $m / s^{2}$.

The laws of motion of the landslide model, used during the experiments, have been calculated by using the theoretical solutions provided by Pelinovsky and Poplavsky (1996) that solved analytically the forces balance acting on a moving submerged body providing also the theoretical equations for both the displacement $s(t)$ and the velocity $u(t)$ of the submerged landslide body as a function of the initial acceleration $a_{0}$ and the terminal velocity $u_{t}$ of the body itself. The equations for the displacement $s(t)$ and the velocity $u(t)$ of the submerged landslide read as follows:

$$
\begin{gathered}
s(t)=\frac{u_{t}^{2}}{a_{0}} \ln \left[\cosh \left(\frac{a_{0} t}{u_{t}}\right)\right], \\
u(t)=u_{t} \tanh \left(\frac{a_{0} t}{u_{t}}\right),
\end{gathered}
$$

where $t$ is the elapsed time. It has to be stressed that equations (2)-(3) describe the displacement and velocity of gravity-driven landslides that are triggered by different mechanisms other than gravity. Indeed, the terminal velocity $u_{t}$ has been taken constant, as it is related to the hydrodynamic features of the landslides (i.e. drag and added mass coefficients).

Figure 3 shows the displacement $s(t)$ (upper panel) and the velocity $u(t)$ (lower panel) of the landslide model, as obtained by equations (2)-(3), that have been used during the experiments for the four initial accelerations. The initial position was kept constant in such a way the whole of the landslide model is submerged in its rest configuration (see Figure 2). 

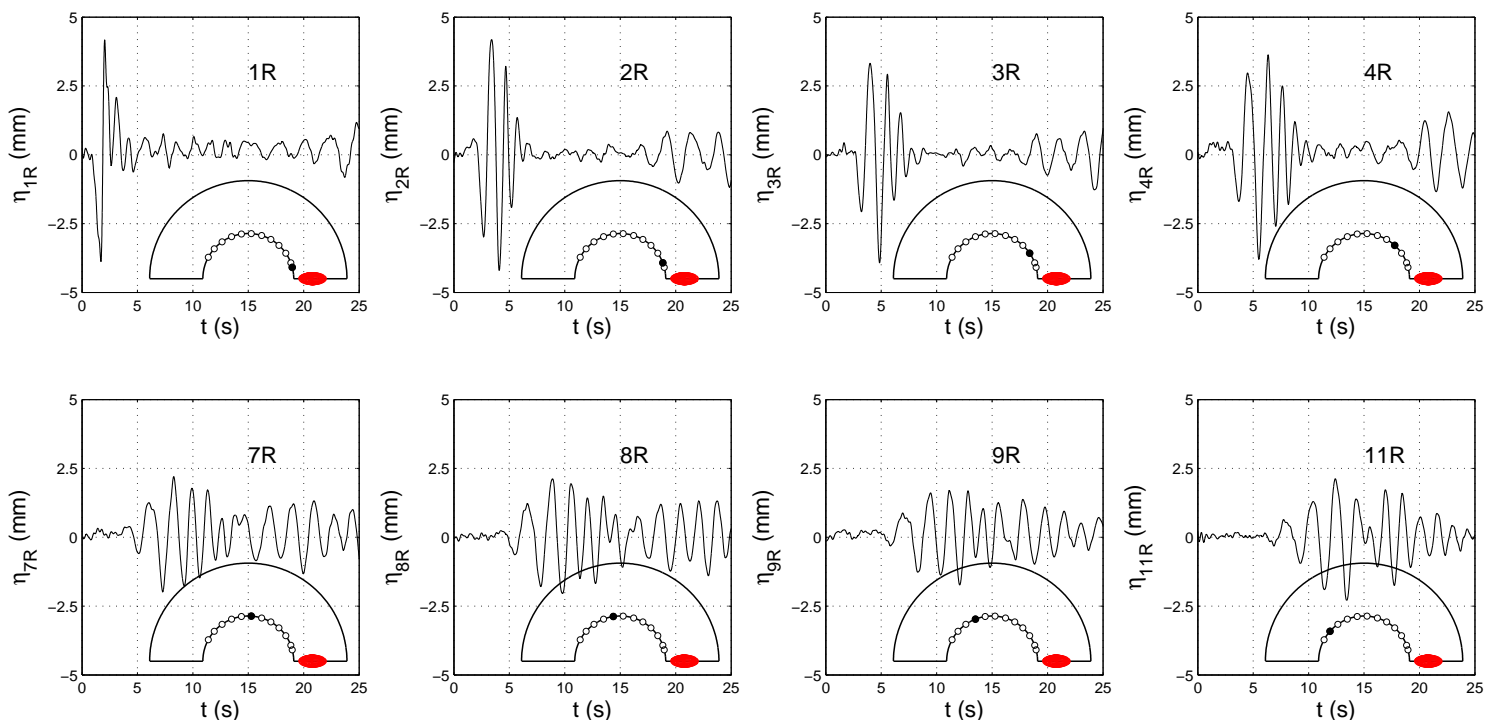

Figure 4: Time series collected by means of run-up gauges $\left(a_{0}=\mathbf{0 . 8} \mathrm{m} / \mathrm{s}^{2}\right)$. Empty circles indicate the location of the run-up gauges, the solid circles in each plot indicate the run-up gauge the plot refers to.
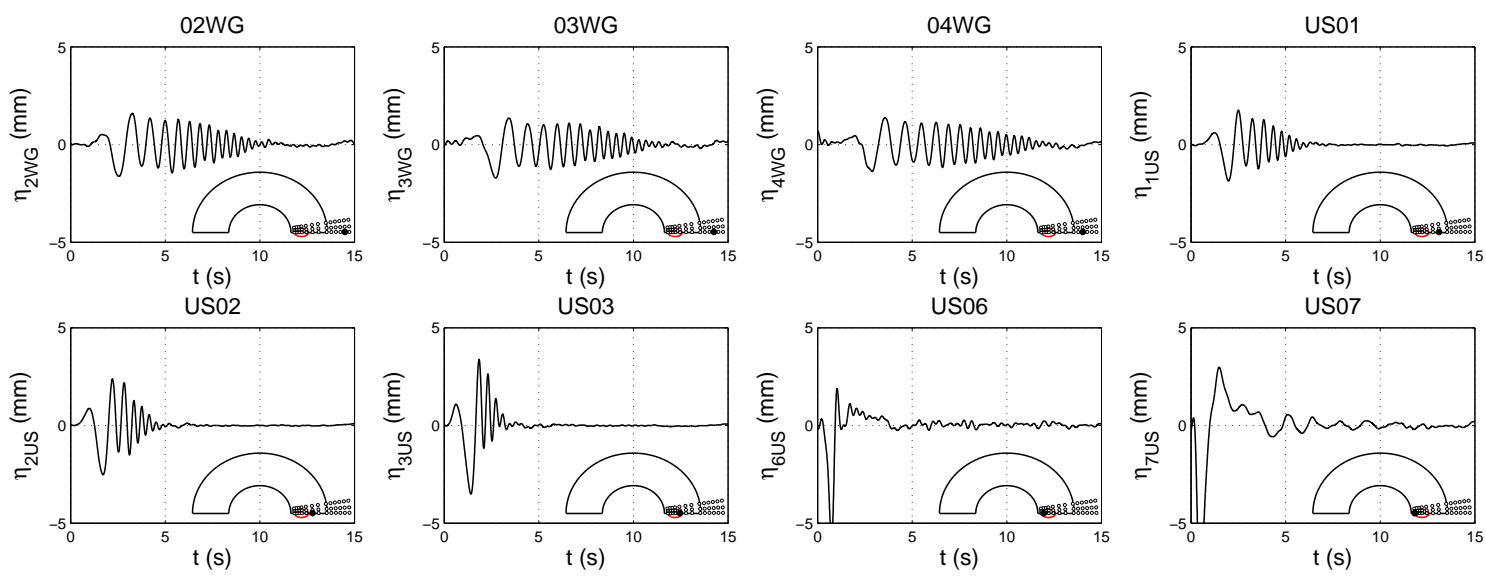

Figure 5: Time series collected by means of sensors deployed on the movable frame $\left(a_{0}=\mathbf{0 . 8} \mathrm{m} / \mathrm{s}^{2}, \theta=\mathbf{0}^{\circ}\right)$. Empy circles indicate the location of sensors, the solid circles in each plot indicate the sensor the plot refers to.

\section{RESULTS AND DISCUSSIONS}

In this section an overview of the preliminary results of the experiments is given. As previously mentioned, the free surface elevation time series have been collected in the near-field (i.e. close to the generation area) by using the movable frame and along the shoreline of the island (i.e. run-up time series).

Figure 4 shows an example of the run-up time series, measured along the shoreline at increasing distances with respect to the generation area, as obtained for $a_{0}=0.8 \mathrm{~m} / \mathrm{s}^{2}$. The time series show that the tsunamis wave packet is characterized by a pronounced leading wave trough close to the generation area (e.g. run-up gauges 1R, 2R). As far as the distance increases (i.e., moving away from the generation area), the amplitude of the leading wave trough decreases. This is consistent with the frequency dispersion mechanisms already pointed out for subaerial landslides that occur at a circular shoreline island (e.g. Di Risio et al., 2009b; Romano et al., 2013, 2016).

As far as the wave pattern in the near-field is considered, the Figure 5 is presented. It shows an example of the free surface elevation time series, measured by the sensors deployed on the movable frame for $\theta=$ 


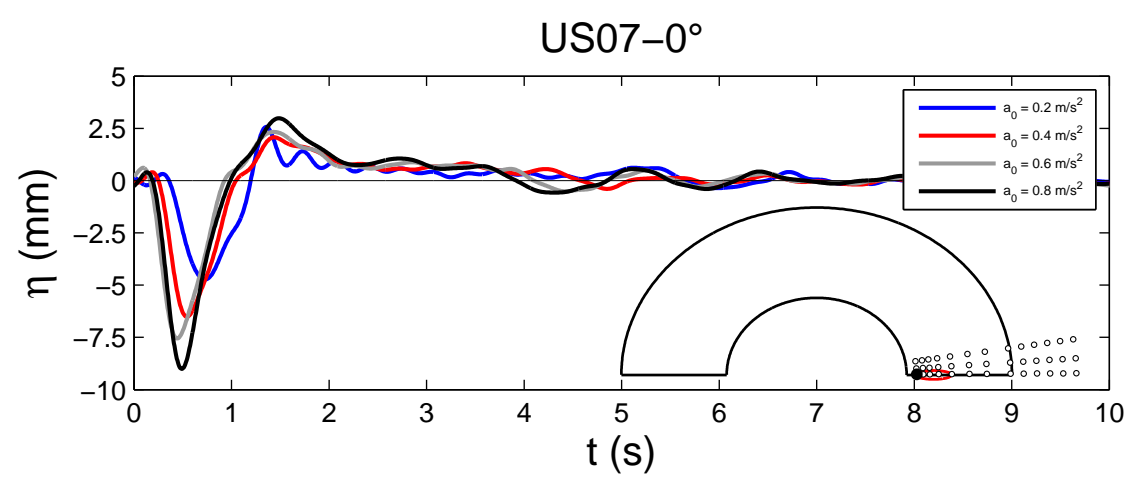

Figure 6: Time series collected by means of the sensor deployed close to the generation area (US07, $\theta=0^{\circ}$ ). Empy circles indicate the location of all sensors, while the solid circle in each plot indicate the sensor the plot refers to.

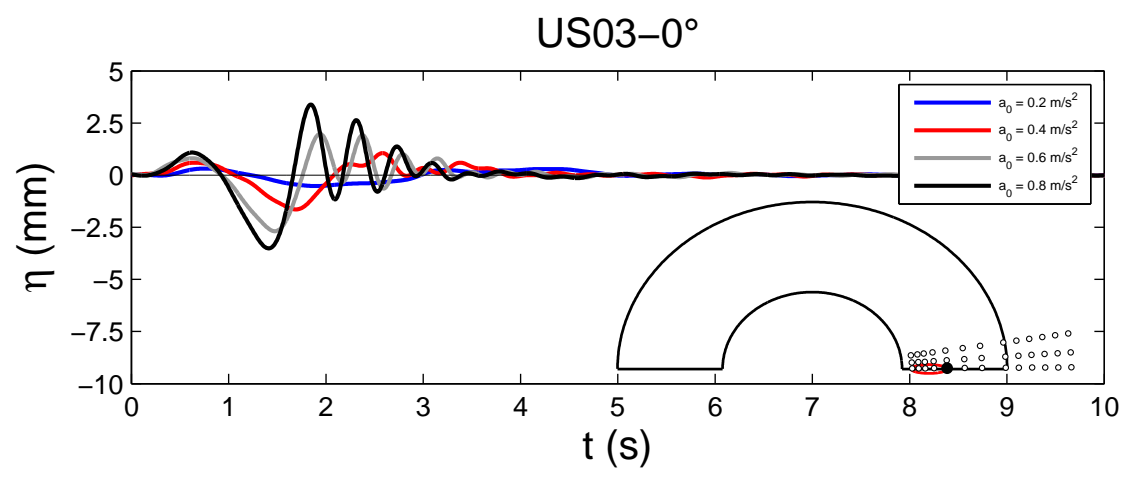

Figure 7: Time series collected by means of the sensor deployed just offshore to the generation area (US03, $\theta=\mathbf{0}^{\circ}$ ). Empy circles indicate the location of all sensors, while the solid circle in each plot indicate the sensor the plot refers to.

$0^{\circ}$ (i.e. when the frame is collinear to the landslide path), as obtained for the initial acceleration $a_{0}=0.8$ $\mathrm{m} / \mathrm{s}^{2}$. It is worth noticing that the features of the time series depend on the location of the wave gauges. The free surface elevation time series measured by the wave gauges deployed close to the shore (i.e. above the initial position of the landslide) exhibit a leading large wave trough, while those instruments placed at increasing distances from the shoreline (i.e. seaward with respect to the initial position of the landslide) are characterized by a leading wave crest followed by trailing waves that radiate away from the coast.

Figure 6 shows the superposition of the free surface elevation time series measured by the ultrasound sensor US07 (the closest to the shoreline) for $\theta=0^{\circ}$ as a function of the four tested initial accelerations $a_{0}$ : the higher the initial acceleration $a_{0}$, the higher the characteristic amplitudes of the generated waves (i.e. both wave crests and wave troughs). Furthermore, it appears that the wave period decreases as the the initial acceleration $a_{0}$ increases.

The same wave features can be inferred by looking at Figure 7 that shows the superposition of the free surface elevation time series measured by the ultrasound sensor US03 (placed just offshore the generation area, at a distance of $1.03 \mathrm{~m}$ from the shoreline) for $\theta=0^{\circ}$ as a function of the four tested initial accelerations. As the gauge is not placed directly above the initial position of the landslide, the wave packet is characterized by a leading wave crest.

Figure 8 shows the comparison between the new experimental data presented herein and the theoretical formulae proposed by Watts (1998) and Watts et al. (2005). The Figure 8 is presented in the form of a wavemaker curve, as proposed by Watts (1998) (see Figure 6 of the mentioned work). This approach consists in representing the dimensionless maximum amplitude $\eta_{\max } a_{0} / u_{t}^{2}$, being $\eta_{\max }$ the maximum of the absolute value of the free surface elevation, $a_{0}$ the initial acceleration and $u_{t}$ the terminal velocity, as a 


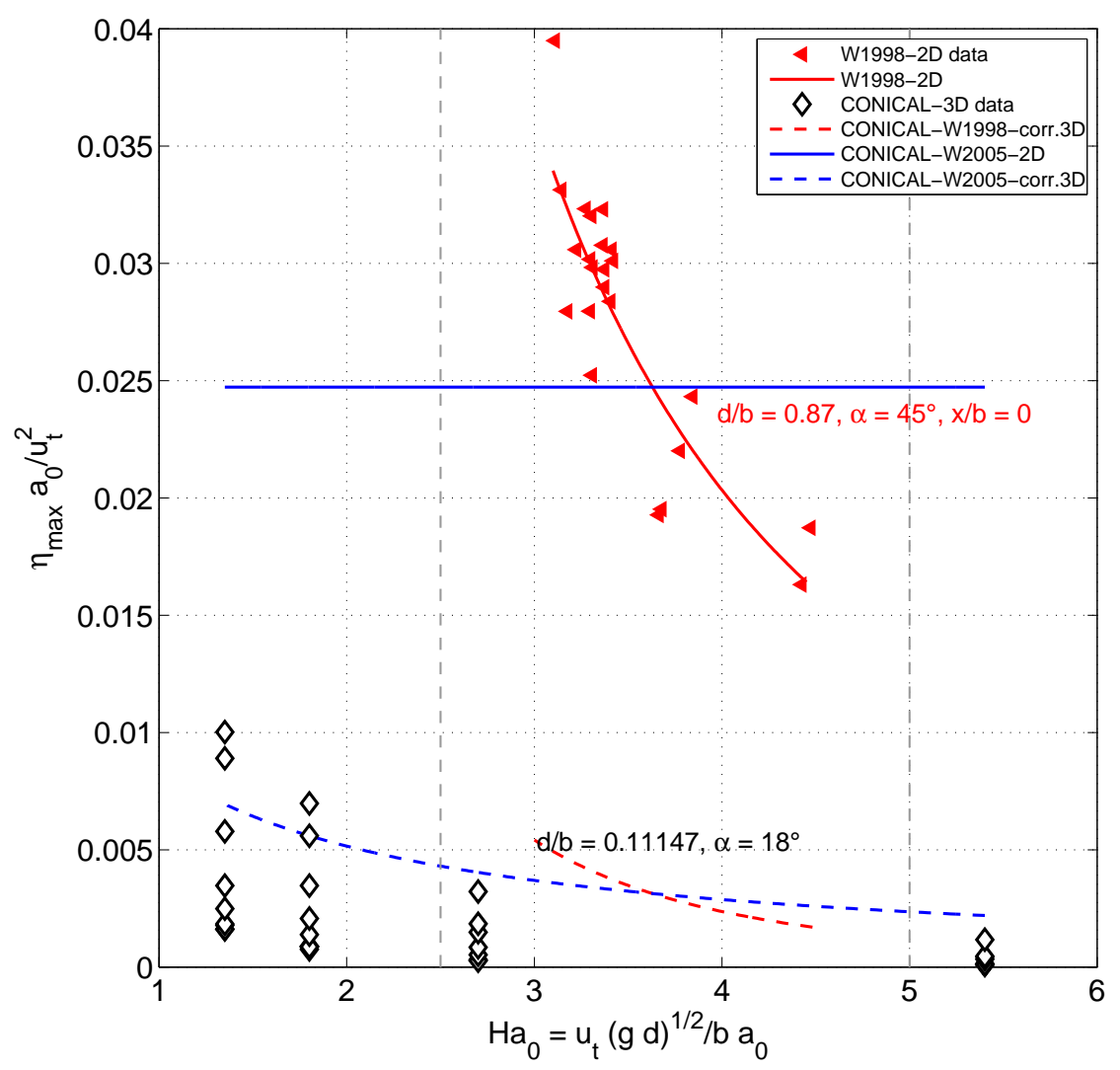

Figure 8: Dimensionless maximum amplitude as a function of the Hammack number. Black diamonds refer to the present experimental data; red triangles and red continuous line refer to the original experimental data and to the empirical power law (2D) respectively as obtained by Watts (1998); continuous blue line refers to the empirical formulation (2D) proposed by Watts et al. (2005) applied by using the parameters of the present experiment; red and blue dashed line refer to the empirical formulae proposed by Watts (1998) and Watts et al. (2005) respectively applied by using the parameters of the present experiment and by taking into the correction formula valid for 3D cases proposed by Watts et al. (2005)

function of the Hammack number $H a_{0}=u_{t}(g d)^{1 / 2} /\left(b a_{0}\right)$, being $d$ the initial submergence of the slide and $b$ its length. In Figure 8 several quantities are represented: empty black diamonds refer to the experimental data obtained herein by varying the initial acceleration; solid red triangles and red continuous line refer to the original experimental data and to the empirical power law (valid for 2D cases) respectively as obtained by Watts (1998); continuous horizontal blue line refers to the empirical formulation (valid for 2D cases) proposed by Watts et al. (2005) applied by using the parameters of the present experiment; red and blue dashed line refer to the empirical formulae proposed by Watts (1998) and Watts et al. (2005) respectively applied by using the parameters of the present experiment and by taking into the correction formula valid for 3D cases proposed by Watts et al. (2005); finally, the grey vertical dashed lines refer to the edges of the experimental interval explored by Watts (1998). It could be observed that the experimental data presented herein exhibit comparable values with those obtained by the prediction formulae, although a strict comparison can not be performed due to the differences of the experimental conditions.

\section{CONCLUDING REMARKS AND ONGOING RESEARCH}

The paper presents the description of a new set of three-dimensional experiments reproducing tsunamis generated by submerged landslides sliding down the flanks of conical islands. The problem considered is similar to that involving flank instabilities at small volcanic islands as the Stromboli volcano (Italy). The experiments aimed to gain insight on the role of the initial acceleration $a_{0}$ in the generation process of tsunamis generated by submerged landslides. An innovative system, based on an electric motor, has been employed for controlling the motion of the landslide model and, consequently, for generating impulsive 
waves. The experiments have been carried out in a parametric way by varying the initial acceleration $a_{0}$ of the landslide, aiming at simulating different triggering mechanisms other than the gravity. The near-field waves have been measured with a high-spatial resolution measurement system. The preliminary experimental results confirmed the crucial role of the initial acceleration of the submerged landslide in generating tsunamis.

\section{ACKNOWLEDGEMENTS}

The research described in this paper is funded by the Italian Ministry of Research within the PRIN2007 research project "Development and validation of hydraulic and geologic tools for supporting a Tsunami Early Warning System. Implementation to the Stromboli (Eolie) landslide case". Mario Nardi and Lucio Matergia, the technicians of LIAM (University of L'Aquila), are acknowledged for their skills in building physical models.

\section{References}

G. Bellotti, M. Di Risio, and P. De Girolamo. Feasibility of tsunami early warning systems for small volcanic islands. Natural Hazards and Earth System Science, 9(6):1911-1919, 2009.

M. Briggs, C. Synolakis, G. Harkins, and S. Hughes. Large scale three-dimensional laboratory measurements of tsunami inundation. Advances In Natural And Technological Hazards Research, 4:129-150, $1995 b$.

M. Briggs, C. Synolakis, G. Harkins, and D. Green. Laboratory Experiments of tsunami runup on a circular island. Pure And Applied Geophysics, 144(3-4):569-593, AUG 1995a. ISSN 0033-4553. doi: \{10.1007/ BF00874384\}.

C. Cecioni and G. Bellotti. Modeling tsunamis generated by submerged landslides using depth integrated equations. Applied Ocean Research, 32(3):343-350, 2010.

C. Cecioni, A. Romano, G. Bellotti, M. Di Risio, and P. de Girolamo. Real-time inversion of tsunamis generated by landslides. Nat. Hazards Earth Syst. Sci, 11:2511-2520, 2011.

Y.-S. Cho and P. L. F. Liu. Crest-length effects in nearshore tsunami run-up around islands. J. Geophys. Res., 104(C4):7907-7913, 1999. ISSN 0148-0227. doi: 10.1029/1999JC900012.

Y.-S. Cho, K.-Y. Park, and T.-H. Lin. Run-up heights of nearshore tsunamis based on quadtree grid system. Ocean Engineering, $31(8$ - 9):1093 - 1109, 2004. ISSN 0029-8018. doi: 10.1016/j.oceaneng.2003.10. 011.

P. De Girolamo, M. Di Risio, A. Romano, and M. Molfetta. Landslide tsunami: physical modeling for the implementation of tsunami early warning systems in the mediterranean sea. Procedia Engineering, 70: 429-438, 2014.

M. Di Risio and P. Sammarco. Analytical modeling of landslide-generated waves. Journal of waterway, port, coastal, and ocean engineering, 134(1):53-60, 2008.

M. Di Risio, P. De Girolamo, and G. Beltrami. Forecasting landslide generated tsunamis: a review. The Tsunami Threat - Research and Technology, Nils-Axel Marner (Ed.), 2011.

M. Di Risio, G. Bellotti, A. Panizzo, and P. De Girolamo. Three-dimensional experiments on landslide generated waves at a sloping coast. Coastal Engineering, 56(5-6):659-671, MAY-JUN 2009a. ISSN 0378-3839. doi: $\{10.1016 /$ j.coastaleng.2009.01.009\}.

M. Di Risio, P. De Girolamo, G. Bellotti, A. Panizzo, F. Aristodemo, M. G. Molfetta, and A. F. Petrillo. Landslide-generated tsunamis runup at the coast of a conical island: New physical model experiments. Journal of Geophysical Research-Oceans, 114, JAN 20 2009b. ISSN 0148-0227. doi: $\{10.1029 / 2008 \mathrm{JC} 004858\}$. 
F. Enet and S. T. Grilli. Experimental study of tsunami generation by three-dimensional rigid underwater landslides. Journal Of Waterway Port Coastal And Ocean Engineering-ASCE, 133(6):442-454, NOVDEC 2007. ISSN 0733-950X. doi: \{10.1061/(ASCE)0733-950X(2007)133:6(442)\}.

F. Enet, S. T. Grilli, P. Watts, et al. Laboratory experiments for tsunamis generated by underwater landslides: comparison with numerical modeling. In The Thirteenth International Offshore and Polar Engineering Conference. International Society of Offshore and Polar Engineers, 2003.

H. M. Fritz, F. Mohammed, and J. Yoo. Lituya bay landslide impact generated mega-tsunami 50th anniversary. Pure and Applied Geophysics, 166(1-2):153-175, 2009.

H. M. Fritz, J. V. Hillaire, E. Molière, Y. Wei, and F. Mohammed. Twin tsunamis triggered by the 12 january 2010 haiti earthquake. Pure and Applied Geophysics, pages 1-12, 2012.

S. T. Grilli and P. Watts. Underwater Landslide Shape, Motion, Deformation, and Tsunami Generation. In EGS - AGU - EUG Joint Assembly, page 13216, 2003.

S. T. Grilli and P. Watts. Tsunami generation by submarine mass failure. i: Modeling, experimental validation, and sensitivity analyses. Journal of waterway, port, coastal, and ocean engineering, 131(6): 283-297, 2005.

V. Heller and J. Spinneken. On the effect of the water body geometry on landslide-tsunamis: Physical insight from laboratory tests and $2 \mathrm{~d}$ to $3 \mathrm{~d}$ wave parameter transformation. Coastal Engineering, 104: 113-134, 2015.

V. Heller, M. Bruggemann, J. Spinneken, and B. D. Rogers. Composite modelling of subaerial landslidetsunamis in different water body geometries and novel insight into slide and wave kinematics. Coastal Engineering, 109:20-41, 2016.

R. S. Johnson. Edge waves: theories past and present. Philosophical Transactions Of The Royal Society A-Mathematical Physical And Engineering Sciences, 365(1858):2359-2376, SEP 15 2007. ISSN 1364503X. doi: $\{10.1098 /$ rsta.2007.2013\}.

P.-F. Liu, T.-R. Wu, F. Raichlen, C. Synolakis, and J. Borrero. Runup and rundown generated by threedimensional sliding masses. Journal of fluid Mechanics, 536:107-144, 2005.

P. L. F. Liu, Y.-S. Cho, M. J. Briggs, U. Kanoglu, and C. E. Synolakis. Runup of solitary waves on a circular island. Journal of Fluid Mechanics, 302:259-285, 1995. doi: 10.1017/S0022112095004095.

F. Løvholt, G. Pedersen, C. B. Harbitz, S. Glimsdal, and J. Kim. On the characteristics of landslide tsunamis. Phil. Trans. R. Soc. A, 373(2053):20140376, 2015. doi: \{10.1098/rsta.2014.0376\}.

P. Lynett and P. L. F. Liu. A numerical study of the run-up generated by three-dimensional landslides. Journal of Geophysical Research-Oceans, 110(C3), MAR 8 2005. ISSN 0148-0227. doi: \{10.1029/ 2004JC002443\}.

B. C. McFall and H. M. Fritz. Physical modelling of tsunamis generated by three-dimensional deformable granular landslides on planar and conical island slopes. In Proc. R. Soc. A, volume 472, page 20160052. The Royal Society, 2016.

F. Mohammed and H. M. Fritz. Physical modeling of tsunamis generated by three-dimensional deformable granular landslides. Journal of Geophysical Research: Oceans (1978-2012), 117(C11), 2012.

F. Montagna, G. Bellotti, and M. Di Risio. 3d numerical modeling of landslide-generated tsunamis around a conical island. Natural hazards, 58(1):591-608, 2011.

A. Panizzo, P. De Girolamo, M. Di Risio, A. Maistri, and A. Petaccia. Great landslide events in italian artificial reservoirs. Natural Hazards and Earth System Science, 5(5):733-740, 2005. doi: 10.5194/ nhess-5-733-2005. 
E. Pelinovsky and A. Poplavsky. Simplified model of tsunami generation by submarine landslides. Physics and Chemistry of The Earth, 21(1 - 2):13 - 17, 1996.

E. Renzi and P. Sammarco. Landslide tsunamis propagating around a conical island. Journal of Fluid Mechanics, 650:251-285, MAY 10 2010. ISSN 0022-1120. doi: \{10.1017/S0022112009993582\}.

A. Romano. Landslide-generated tsunamis around a conical island: The edge waves role. In The Twentyfourth International Ocean and Polar Engineering Conference. International Society of Offshore and Polar Engineers, 2014.

A. Romano, G. Bellotti, and M. Di Risio. Wavenumber-frequency analysis of the landslide-generated tsunamis at a conical island. Coastal Engineering, 81:32-43, 2013.

A. Romano, M. Di Risio, G. Bellotti, M. Molfetta, L. Damiani, and P. De Girolamo. Tsunamis generated by landslides at the coast of conical islands: experimental benchmark dataset for mathematical model validation. Landslides, 13(6):1379-1393, 2016.

P. Sammarco and E. Renzi. Landslide tsunamis propagating along a plane beach. Journal of Fluid Mechanics, 598:107-119, MAR 10 2008. ISSN 0022-1120. doi: \{10.1017/S0022112007009731\}.

C. E. Synolakis, J.-P. Bardet, J. C. Borrero, H. L. Davies, E. A. Okal, E. A. Silver, S. Sweet, and D. R. Tappin. The slump origin of the 1998 papua new guinea tsunami. Proceedings of the Royal Society of London. Series A: Mathematical, Physical and Engineering Sciences, 458(2020):763-789, 2002. doi: 10.1098/rspa.2001.0915.

S. Tinti, A. Manucci, G. Pagnoni, A. Armigliato, and F. Zaniboni. The 30 December 2002 landslide-induced tsunamis in Stromboli: sequence of the events reconstructed from the eyewitness accounts. Natural Hazards and Earth System Science, 5(6):763-775, Oct 2005. URL http://hal.archives-ouvertes.fr/ hal-00299290.

S. Tinti, G. Pagnoni, and F. Zaniboni. The landslides and tsunamis of the 30th of december 2002 in stromboli analysed through numerical simulations. Bulletin of Volcanology, 68:462-479, 2006. ISSN 0258-8900. URL http://dx.doi.org/10.1007/s00445-005-0022-9. 10.1007/s00445-005-0022-9.

F. Ursell. Edge waves on a sloping beach. Proceedings of the Royal Society of London. Series A. Mathematical and Physical Sciences, 214(1116):79-97, 1952. doi: 10.1098/rspa.1952.0152.

P. Watts. Wavemaker curves for tsunamis generated by underwater landslides. Journal of Waterway, Port, Coastal, and Ocean Engineering, 124(3):127-137, 1998. doi: 10.1061/(ASCE)0733-950X(1998)124: 3(127).

P. Watts, S. Grilli, D. Tappin, and G. Fryer. Tsunami generation by submarine mass failure. ii: Predictive equations and case studies. Journal of Waterway, Port, Coastal, and Ocean Engineering, 131(6):298310, 2005. doi: 10.1061/(ASCE)0733-950X(2005)131:6(298).

H. Yeh, P. L. F. Liu, M. Briggs, and C. E. Synolakis. Propagation and amplification of tsunamis at coastal boundaries. Nature, 372(6504):353-355, Nov. 1994. doi: 10.1038/372353a0.

G. Zitti, C. Ancey, M. Postacchini, and M. Brocchini. Impulse waves generated by snow avalanches: Momentum and energy transfer to a water body. Journal of Geophysical Research: Earth Surface, 2016. 